\title{
SEISMIC PERFORMANCE IMPROVEMENT OF THE BELL TOWER IN SERRA S.QUIRICO BY COMPOSITES
}

\author{
EDOARDO COSENZA AND IUNIO IERVOLINO \\ Dept. of Structural Analysis and Design, University of Naples Federico II \\ via Claudio 21, 80125 Naples - Italy \\ ENRICO GUGLIELMO \\ Head of State Office for Architectural and Environmental Heritage of Naples \\ Palazzo Reale, Piazza del Plebiscito, 80100 Naples - Italy
}

Masonry ancient buildings are relevant part of Italian cultural and architectural heritage. These structures spend their lives trough the centuries being subjected to several dangerous environmental events as earthquakes. After the recent 1997 Umbria-Marche earthquake many historically and architecturally important buildings experienced wide damages and losses.

Due to recent architectural restoration guidelines any developed intervention must do not change appearance, structural mechanism and must be also invasively limited. These innovative principles, that are quite obvious from a cultural and artistic point of view, are very restrictive constraints to engineers jobs. Furthermore, traditional structural materials may be not suitable for these purposes. Besides, innovative materials as composites, and advanced analysis techniques according with requirements listed above, may be helpful in matching discussed requirements. This philosophy was applied to the design process of the retrofitting intervention for the bell tower of Serra S. Quirico (Ancona - Italy). A light FRP ties system have been gripped on the inner walls; this reinforcing structure is anchored at the base on a formerly built reinforced concrete slab independent of the tower foundation. The FRP installation process was planned to avoid any material removal and also to keep any non-structural element have been as it was. In the present paper suitability of innovative composite materials in structural rehabilitation of historical buildings is demonstrated by describing on site dynamic preliminary tests, intervention principles, design and construction processes for an important masonry bell tower.

\section{INTRODUCTION}

While the repair and reconstruction of damages by Friuli (1976) and Irpinia-Basilicata (1980-1981) earthquakes was still going on, new technical regulation, oriented to seismic adjustment of building, was promulgated in Italy. It dealt with the idea of "performing several interventions in order to 
make the structure resistant to the seismic actions”. Those interventions, based on reinforced concrete and construction steel bars, appeared extremely harmful for structures belonging to the architectural heritage provoking irreversible damages.

Construction steel, for example, was commonly putted in masonry structures; its volumetric expansion due corrosion induced wide cracking in the retrofitted elements.

After the assessment of damages of those "seismic adjustment" following the regulations, members of National Committee for Cultural Heritage Seismic Risk Prevention (created by the Environmental and Cultural Department in the 1986) claimed the principle of seismic improvement, instead of seismic adjustment, by techniques respecting the structural system and preserving their integrity.

This way of thinking have been clearly claimed by 16.1. 196 decree that explain the mandatory seismic improvement for historically-artisitically relevant structures as "interventions on the structural elements of the building in order to increase the safety margin without changing the main features of global behaviour".

It's worth noting that is not possible to get completely removable interventions keeping their structural effectiveness; this is why the listed principles are should be called "asymptotic" concepts. Innovative structural materials are helpful in the matter. Varying composites matrices quantities, fibres types and relative percentage, several structural problems can be addressed; it opens new scenarios for engineers. Industrial processing and economical reasons only, limit these new structural capabilities.

Continuous fibres composites, due to their lightness, strength and durability features, are particularly powerful. The intervention described in the following shows it.

The focused structure is an aging bell tower affected by the Umbria-Marche earthquake (1997). the S. Lucia's church bell tower is a sac-masonry structure built during the xv century. It is a very tall structure (approx. $32 \mathrm{~m}$; 1100 tons in weight) at the centre of the little town of serra S. Quirico that is a mid-age suburb near ancona (see Figure 1a).

To improve the structural seismic strength, inner steel beams reticular system anchored to the masonry was formerly designed. It was concepted to be a fully substitutive structures in case of earthquake.

It would need the removal of existing wood floors and their replacement by steel panels and anchoring of steel profiles in the masonry also.

As the designed intervention strongly breaks the concepts of structural restoration cultural heritage department authorities rejected this proposal due to its structural invasivity. Then the former supervisor to the 
architectural heritage of Marche, Arch. Enrico Guglielmo, asked Professor Edoardo Cosenza consulting for a solution by innovative materials. The whole process, including installation of composites, finished in the summer of 2002. In the following preliminary structural investigations, the design process and realization phases are described.
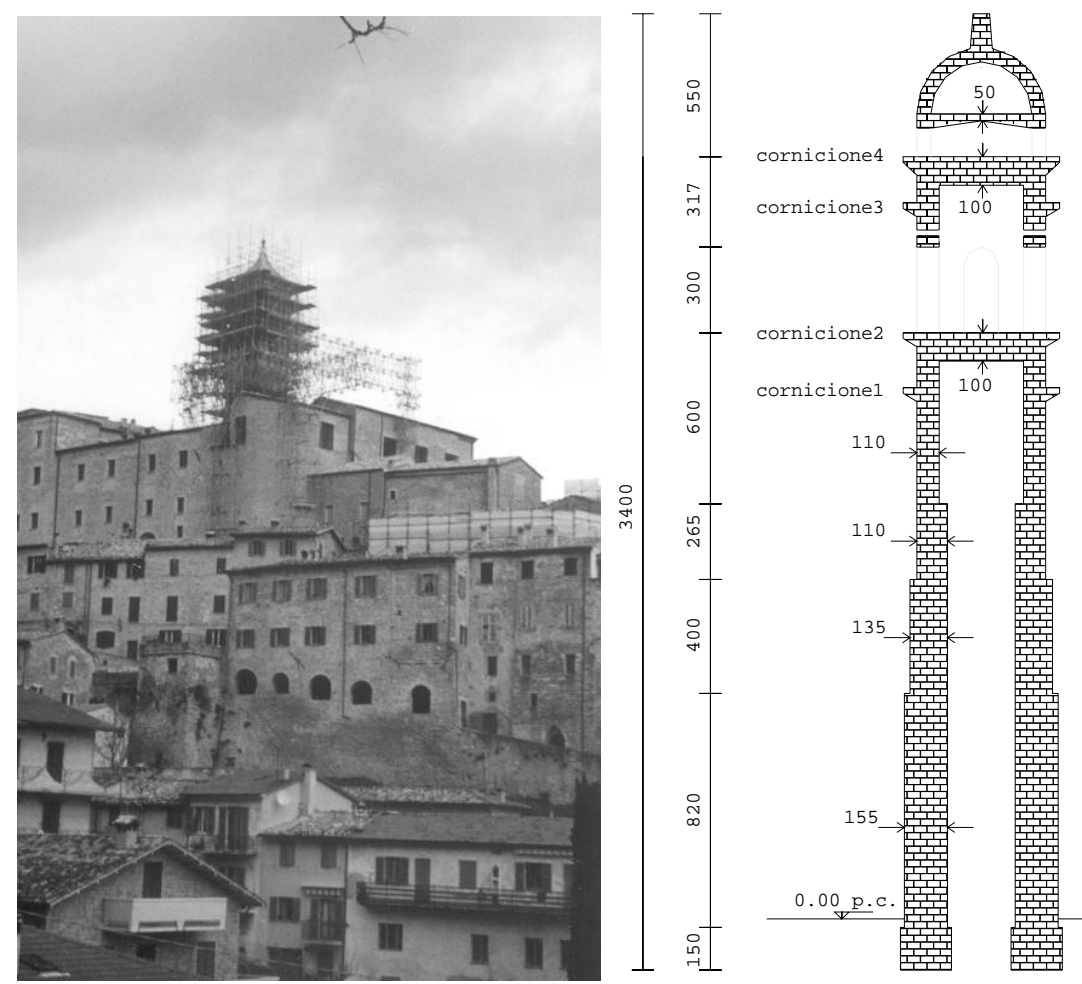

Figure 1. The bell tower in Serra S. Quirico and its structural section.

\section{STRUCTURAL INVESTIGATIONS}

Since the structure is completely surrounded by buildings uncertainty about the whole dynamic behaviour were added to the traditional uncertainties associated with materials features and conditions. Experimental tests were then carried to obtain data on the constraining level between the tower and the adjoining buildings (mainly the S. Lucia's Church and its cluster). The tests described elsewhere ${ }^{1}$, comprised the following tasks:

1. Simple linear continuous and concentrated mass models set up by the technical literature to preliminary assess the modal behaviour. 
2. Detailed 3D finite elements structural modelling (see Figure 3) based on the relief performed by the task force (33000 nodes; 27000 elements pre-processed with Altair HyperMesh 4.0 software).

3. Numerical study to get vibration frequencies and modal shapes considering the presence and absence of lateral constraints.

4. Forced vibration test using a vibration machine and wind action. Using very accurate accelerometers allowed low excitation energies avoiding damages to the painted church and the cluster.

5. Comparison of numerical and experimental results help getting material mechanical properties and whole structural behaviour ${ }^{2}$.

Experimental and numerical analyses are summarized in Table 1. The results in terms of natural frequencies and shapes clearly show constrain from surrounding buildings.

Table 1. Experimental and numerical dynamic analyses comparison.

\begin{tabular}{cccc}
\hline & $\begin{array}{c}\text { 3D FEM no } \\
\text { constraints }\end{array}$ & $\begin{array}{c}\text { 3D FEM w/o } \\
\text { constraints }\end{array}$ & $\begin{array}{c}\text { Experimental } \\
\text { tests }\end{array}$ \\
\hline I mode & $1.1 \mathrm{~Hz}$ Bending & $2.27 \mathrm{~Hz}$ Bending & $1.95 \mathrm{~Hz}$ Bending \\
II mode & $1.13 \mathrm{~Hz}$ Bending & $2.40 \mathrm{~Hz}$ Bending & $2.20 \mathrm{~Hz}$ Bending \\
III mode & $4.86 \mathrm{~Hz}$ Bending & $7.21 \mathrm{~Hz}$ Torsional & $6.75 \mathrm{~Hz}$ Torsional \\
\hline
\end{tabular}

Numerical model was used also for static analyses considering weight wind and conventional seismic action ${ }^{3}$. Masonry density $\left(1900 \mathrm{~kg} / \mathrm{m}^{3}\right)$, was evaluated by on site tests, the elasticity modulus was estimated as 2000 $\mathrm{MPa}$; this value was also confirmed by dynamic analyses.

In Figure 2 modal shapes coming out from 3D FEM analysis are plotted for the first three modes in both the free and side-constrained subcases. 

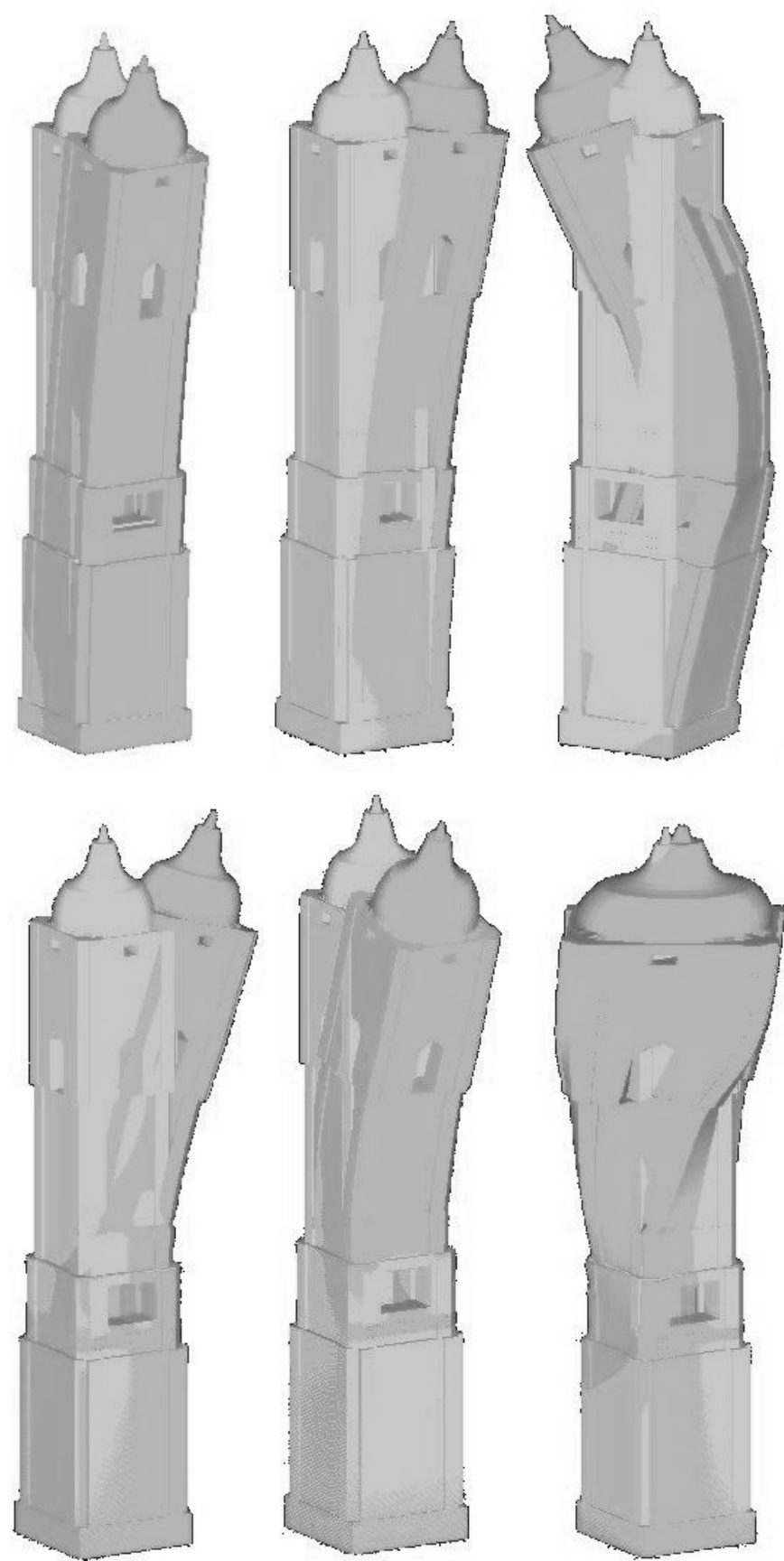

(a)

(b)

Figure 2. F.E. modal analysis for free (a) and constrained (b)conditions. 


\section{RETROFITTING DESIGN}

Design process intended to get the principles listed above, then the planned intervention avoids local masonry failures ${ }^{4}$ and improve the seismic strength of the structure (see Figure 3).

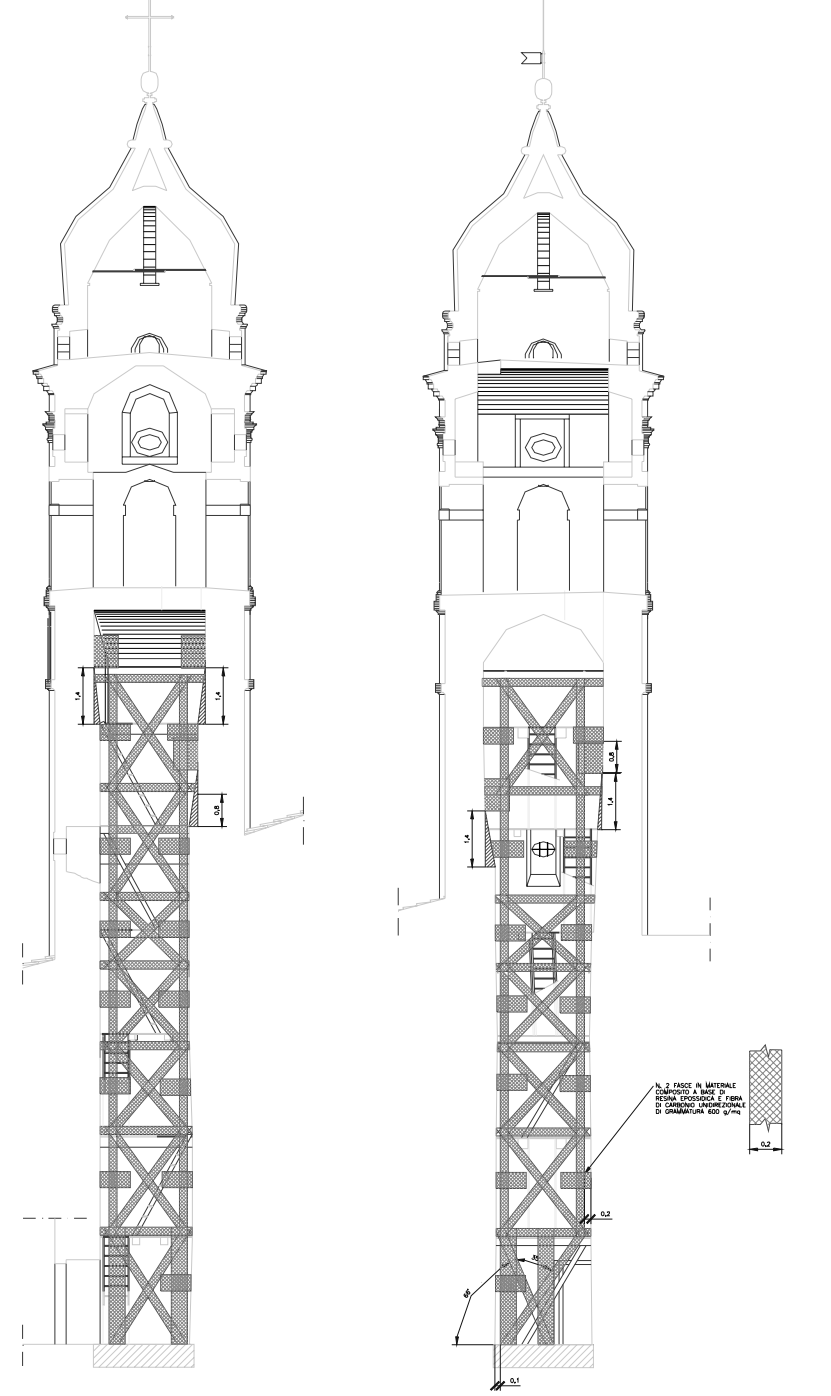

Figure 3. Bell tower composites intervention relief into two sections.

A reticular system, made of horizontal and vertical carbon fibre, was gripped on the inner walls of the tower (see Figure 4). The FRP was 
installed without removing the original wood beams at floors; only wood panels were temporarily removed and restored at the end of the whole process. Horizontal short composite elements were spaced in the walls corners to improve the grip (see Figure 5a). From the structural point of view FRP design aimed to greatly improve seismic capacity of the tower. Usually structural engineering practice neglects masonry tension strength, while FRP ensure a monolithic behaviour for high intensity earthquakes. The structure keeps its static mechanism for low intensity seismic activity because the added stiffness is very low in comparison to the one of the bell tower, but in case of strong motion the tension side of masonry goes loosing cohesion allowing the composites start working; then the masonry behave as reinforced structure. A reinforced concrete slab $(70 \mathrm{~cm}$ thickness, 40 micro poles), built as foundation for formerly proposed steel structure, was used for anchoring composites to the ground without overloading the original tower's foundation. The strength improvement was computed by ultimate limit state analysis. What comes out is that the critical cross section is the one correspondent to the connection between the tower and the church. Applying the composites the overturning moment, considering a ultimate stress in the masonry of $4 \mathrm{Mpa}$, jumps from $1650 \mathrm{tm}$ to $2750 \mathrm{tm}$ (limit strain in the masonry equal to $0.2 \%$ ) or $3000 \mathrm{tm}$ (limit in strain of $0.5 \%$ ), meaning $70-85 \%$ strength improvement. A simplified analysis, considering unlimited masonry strength and full strength development of the FRP, gives an OTM of 1780 without considering intervention, and 3440 tm with composites, meaning a $90 \%$ of strength improvement. The calculations show that this solution gives a higher strength improvement with a very low invasivity. The composites used were made of. $20 \mathrm{~cm}$ wide double layer fabric, 600 $\mathrm{gr} / \mathrm{mq}$ in weight and $0.67 \mathrm{~mm}$ in thickness. A key aspect of the intervention was the composites-masonry grip system, the fabrication details and the anchoring of the composites to the foundations. All those problems were managed by the expertise of professor Alberto Balsamo.

\section{COMPOSITES INSTALLATION}

The composites installation strictly followed the design specifications. Even though the small available space and the presence of the wood beams, the composite textile allowed a simple intervention installation. To obtain a good grip masonry samples were analysed to get the optimum surface treatment. In Figures 4-6 aspects are highlighted. In Figure 4 and $5 \mathrm{~b}$ an anchoring steel plate detail is shown, also the horizontal and oblique elements are displayed close to an original wooden beam. 


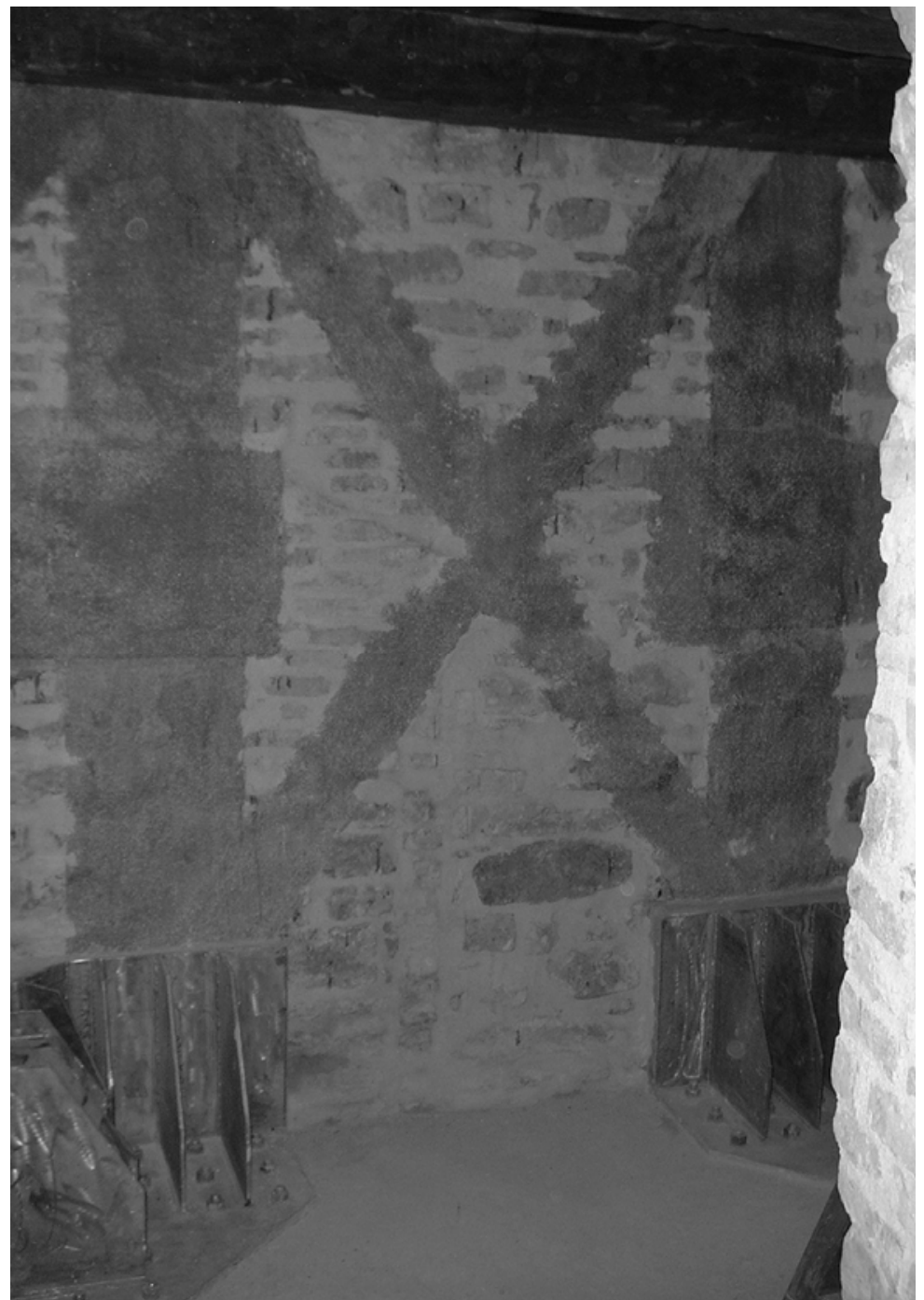

Figure 4. Installed composites and base anchorage.

In Figure 6 another anchoring plate is pictured; it's very stiff since it should not be the weakest element of the whole system. The focused plate is in the most irregular corner of the inner part of the bell tower, and then a large quantity of filling resin was needed. In Figure 5 some details are shown; in the first one there's a horizontal element improving the grip on the masonry. 
In Figure 6 is shown how the composite structural system geometry was locally modified to do not pass over the tower openings.
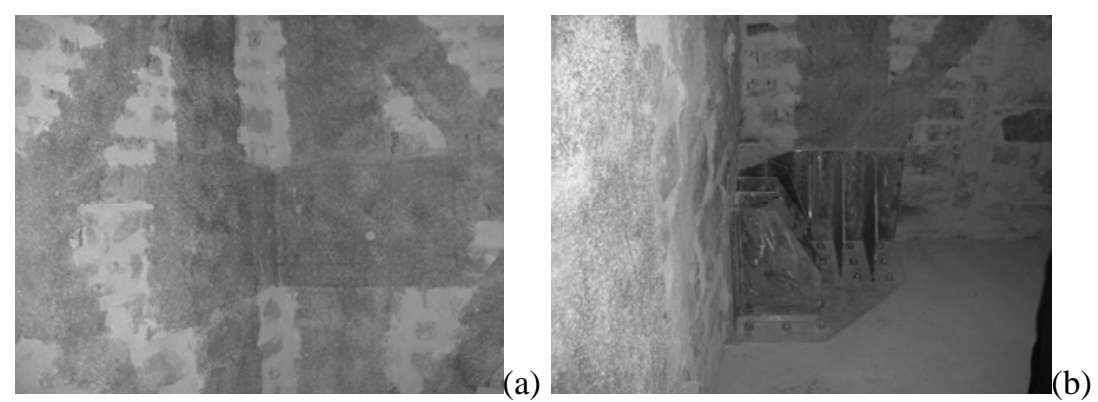

Figure 5. Intervention walls gripping (a) and anchoring details (b).

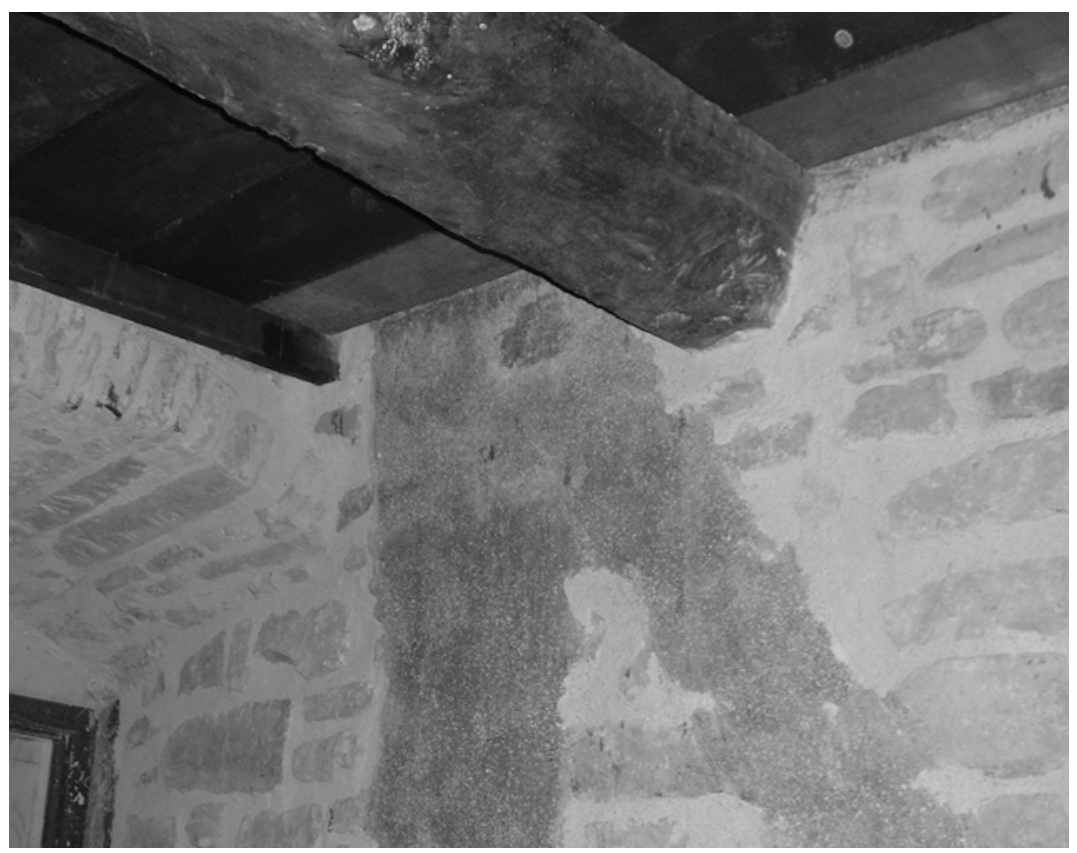

Figure 6. Composites near to unremoved wooden floor.

The lack of pictures brightness in the pictures is due to the achievement of the "transparency" target of the intervention design process: the improvement of structural strength is strong but the installation is "light". 


\section{CONCLUSIONS}

The intervention on the bell tower of the S. Lucia's church is an interesting application of composites in the structural restoration. Transparency and low invasivity target are fully achieved avoiding holes and removal of wooden beams and slabs. In the same time structural target was satisfied also since the seismic strength was greatly increased; the same safety level could be obtained with a heavy steel structure only (corresponding to the rejected former design). The composites are placed directly on the masonry surface so they are removable and almost invisible. The application is a case of fruitful interaction among state offices; architects and engineers trough innovative structural techniques (on site structural identification tests, refined numerical 3D modelling, advanced design using innovative materials). The result is a model procedure for further interventions.

\section{ACKNOWLEDGEMENTS}

The authors acknowledge architects A. Cyrillo Gomes and U. Soragni for relieves and architectural aspects; Ph.E. S. Vitolo for aiding in analyses.

\section{REFERENCES}

[1] T. Pelella, G. Mannara, E. Cosenza, I. Iervolino, L. Lecce: "Structural dynamic investigations on the bell tower from the S.Lucia's church - Serra S. Quirico, Ancona"; $7^{\text {th }}$ Int. Seminar on Seismic Isolation, Passive Energy Dissipation and Active Control of Vibrations of Structures, Assisi, Italy, October 2-5, 2001.

[2] P.Clemente, G. Buffarini, G. Bongiovanni \& D. Rinaldis, "Dynamic characterization of the bell tower of S. Giorgio in Trignano before and after restoration”, ISTHECH Project, Final Workshop.

[3] V. Zabel, C. Bucher, J. Riedel, "The dynamic behaviour of a historical bell tower in situ-test and numerical investigation" , Faculty of Civil Engineering, Institute of Structural Mechanics, Bauhaus University Weimar, Germany.

[4] Bongiovanni G., Clemente P., Buffarini G., "Analysis of the seismic response of damaged masonry bell tower" Proc., 12 the World Conference on Earthquake Engineering, Auckland, 30 Jan-4 Feb 2000. 